\title{
Growth Hormone Release Inhibiting Hormone: Actions on Thyrotrophin and Prolactin Secretion after Thyrotrophin- releasing Hormone
}

\author{
D. CARR, A. GOMEZ-PAN, D. R. WEIGHTMAN, V. C. M. ROY, R. HALL, G. M. BESSER, \\ M. O. THORNER, A. S. MCNEILLY, A. V. SCHALLY, A. J. KASTIN, D. H. COY
}

\section{Patients and Methods}

Six healthy men aged $27-42$ years with no evidence of pituitary or thyroid disease and three patients with varying degrees of primary hypothyroidism ${ }^{10}$ gave their informed written consent to the study.

The cyclic tetradecapeptide GH-RIH was synthesized and purified as described by Coy et al. ${ }^{11}$ Serum TSH was measured by a double antibody radioimmunoassay ${ }^{12}$ using M.R.C. $68 / 38$ as standard and National Pituitary Agency thyrotrophin for iodination. Serum prolactin was estimated by a specific double antibody radioimmunoassay ${ }^{13}$ using a rabbit antihuman prolactin antiserum and purified human pituitary prolactin as standard and for iodination. Serum protein-bound iodine (P.B.I.) was measured by the Technicon AutoAnalyzer and residual binding capacity of serum by the Thyopac3 method (Radiochemical Centre, Amersham); the free thyroxine index (F.T.I.) was calculated from these values. Serum thyroxine (T-4) was measured by the Thyopac-4 method (Radiochemical Centre, Amersham) and serum triiodothyronine (T-3) estimated by radioimmunoassay of unextracted serum. ${ }^{14}$ The data were analysed statistically using Student's $t$ test (two tailed).

\section{Introduction}

Since synthetic ovine growth hormone release inhibiting hormone (GH-RIH) became available it has been shown to inhibit the release of several hormones from the pituitary, ${ }^{1-3}$ the pancreas, and the gastrointestinal tract. ${ }^{4-6}$ Inhibition of the thyrotrophin response to thyrotrophin-releasing hormone (TRH) by GH-RIH was suggested by preliminary experiments ${ }^{1}$ and has since been verified. ${ }^{7-9}$ We further examined the effects of short-term infusions of GH-RIH on basal thyrotrophin levels and on TRH-induced release of thyrotrophin and prolactin in normal people and in patients with primary thyroid failure.

\footnotetext{
Endocrine Unit, Department of Medicine, University of Newcastle upon Tyne, Newcastle upon Tyne NE1 4LP

D. CARR, M.B., M.R.C.P., Senior Registrar in Medicine (Present appointment: Consultant Physician, North Tees General Hospital, Stockton on Tees)

A. GOMEZ-PAN, M.D., Research Associate in Medicine

D. R. WEIGHTMAN, Technician

V. C. M. ROY, M.B., B.S., Research Fellow

R. HALL, M.D., F.R.C.P., Professor of Medicine

Medical Professorial Unit, St. Bartholomew's Hospital, London

G. M. BESSER, M.D., F.R.C.P., Professor of Endocrinology

M. O. THORNER, M.B., M.R.C.P., Research Lecturer in Medicine

A. S. MCNEILLY, PH.D., Research Lecturer in Chemical Pathology

Veterans Administration Hospital and Tulane University School of Medicine, New Orleans, Louisiana, U.S.A.

A. V. SCHALLY, PH.D., Professor of Medicine

A. J. KASTIN, M.D., Professor of Medicine

D. H. COY, PH.D., Assistant Professor of Medicine
}

\section{EXPERIMENTAL DESIGN}

All studies were started between 7 and 9 a.m., with the subjects recumbent after an overnight fast. Forearm venous cannulae for blood sampling and infusions were inserted 30 minutes before the start of the studies. A constant rate infusion pump was used to administer GH-RIH and the control saline infusions. The normal volunteers all underwent the following procedures: (a) infusion of GH-RIH $1000 \mu \mathrm{g}$ alone over 75 minutes; $(b)$ infusion of normal saline $(40 \mathrm{ml})$ over 75 minutes with TRH $200 \mu$ g given as a $2-\mathrm{ml}$ intravenous bolus at 15 minutes; (c) infusion of GH-RIH $100 \mu \mathrm{g}$ over 75 minutes with TRH $200 \mu \mathrm{g}$ intravenous bolus at 15 minutes; $(d)$ infusion of $\mathrm{GH}-$ RIH $1000 \mu \mathrm{g}$ over 75 minutes with TRH $200 \mu \mathrm{g}$ intravenous bolus at 15 minutes, and (e) infusion of GH-RIH $1000 \mu \mathrm{g}$ over 75 minutes with TRH $800 \mu \mathrm{g}$ intravenous bolus at 15 minutes.

Procedures $b, c$, and $d$ were performed in random order using a crossover design and $a$ and $e$ were performed later. At least one week elapsed between procedures. Blood sampling began 15 minutes before the infusion started and continued at intervals for 120 minutes.

Three hypothyroid patients with raised thyrotrophin levels received TRH $200 \mu \mathrm{g}$ as an intravenous bolus with and without GH$\mathrm{RIH}$ as in procedures $b$ and $d$. The order of tests was randomized and one week elapsed between tests. Clinical and biochemical details of these patients are shown in the table.

\section{Results}

NORMAL SUBJECTS

No significant fall was detected in basal thyrotrophin levels in the normal men undergoing GH-RIH infusions, though very small

Clinical and Biochemical Details of Three Patients with varying Degrees of Hypothyroidism

\begin{tabular}{|c|c|c|c|c|c|c|c|c|c|}
\hline $\begin{array}{l}\text { Case } \\
\text { No. }\end{array}$ & Sex & Age & Grade & $\begin{array}{c}\text { P.B.I. } \\
\text { (nmol/1) }\end{array}$ & Thyopac-3 & F.T.I. & $\underset{(\mathrm{mU} / \mathrm{l}) \dagger}{\substack{\text { Basal TSH }\\
}}$ & $\begin{array}{c}\mathrm{T}-4 \\
(\mathrm{nmol} / \mathrm{l})\end{array}$ & $\begin{array}{c}\mathrm{T}-3 \\
(\mathrm{nmol} / \mathrm{l})\end{array}$ \\
\hline $\begin{array}{l}1 \\
2 \\
3\end{array}$ & $\begin{array}{l}\text { M. } \\
\text { F. } \\
\text { F. }\end{array}$ & $\begin{array}{l}28 \\
34 \\
51\end{array}$ & $\begin{array}{l}\text { Subclinical } \\
\text { Mild } \\
\text { Overt }\end{array}$ & $\begin{array}{l}567 \\
213 \\
489^{*}\end{array}$ & $\begin{array}{l}102 \\
132 \\
131\end{array}$ & $\begin{array}{l}7 \cdot 1 \\
2 \cdot 0 \\
4 \cdot 7\end{array}$ & $\begin{array}{l}15.0 \\
21.7 \\
29.5\end{array}$ & $\begin{array}{r}51.5 \\
20.6 \\
5.2\end{array}$ & $\begin{array}{c}0.78 \\
0.78 \\
\text { Undetectable }\end{array}$ \\
\hline
\end{tabular}

*The normal P.B.I. in this patient was due to circulating iodoprotein known to be secreted in Hashimoto's disease.

$+95 \%$ of normal people have TSH levels $<6 \mathrm{mU} / \mathrm{l}$.

Conversion: SI to Traditional Units-P.B.I.: $100 \mathrm{nmol} / 1 \approx 1 \cdot 27 \mu \mathrm{g} / 100 \mathrm{ml} . \mathrm{T}-4: 1 \mathrm{nmol} / 1 \approx 0.078 \mu \mathrm{g} / 100 \mathrm{ml}$. T-3: $1 \mathrm{nmol} / 1 \approx 0.65 \mathrm{ng} / \mathrm{ml}$. 
changes in serum thyrotrophin within the normal range may not have been detected in our radioimmunoassay. Thyrotrophin levels did not fall below the limit of detection of the assay in any person.

After a $200-\mu \mathrm{g}$ injection of TRH the normal rise in serum thyrotrophin was significantly impaired in all subjects when GH-RIH $1000 \mu \mathrm{g}$ was infused (at a rate of $13.3 \mu \mathrm{g} / \mathrm{min}$ ). The lower dose of $100 \mu \mathrm{g}$ (at $1.3 \mu \mathrm{g} / \mathrm{min}$ ), which was given to five men, failed to suppress the TRH-mediated thyrotrophin release in one man and in the other four caused a smaller reduction than the higher dose. The mean result in the five normal subjects is shown in fig. 1. For statistical analysis the basal thyrotrophin value was taken as the mean of the values at -15 and 0 minutes and the peak was considered as the mean of those obtained at 35,40 , and 45 minutes. There was a significant difference between the rise in thyrotrophin on the control day (saline infusion) and when GH-RIH $1000 \mu \mathrm{g}$ was given $(\mathrm{P}<0.001)$ and also when GH-RIH $100 \mu \mathrm{g}$ was given $(\mathrm{P}<0.05)$. We observed no significant rebound in thyrotrophin levels after stopping the GH-RIH infusion such as has been reported by others. ${ }^{8}$

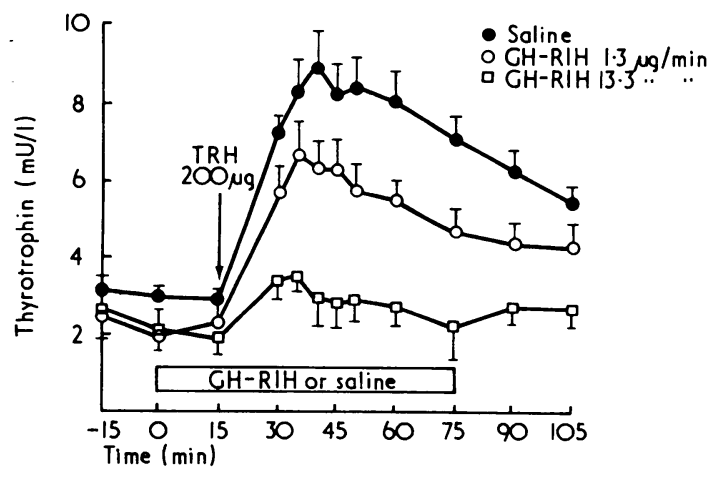

FIG. 1-Effects of GH-RIH and saline on TRH-mediated thyrotrophin release. Results are mean data ( \pm S.E.) from five normal men.

There were no differences in the thyrotrophin increments using $200 \mu \mathrm{g}$ or $800 \mu \mathrm{g}$ injections of TRH during the high-dose infusion of GH-RIH, but the effect of both doses of TRH on thyrotrophin release was impaired by GH-RIH.

The TRH-mediated prolactin release was not significantly affected by GH-RIH (fig. 2). At a constant infusion rate of GH-RIH of $13.3 \mu \mathrm{g} / \mathrm{min}$ the prolactin response to 200 or $800 \mu \mathrm{g}$ of TRH was almost identical.

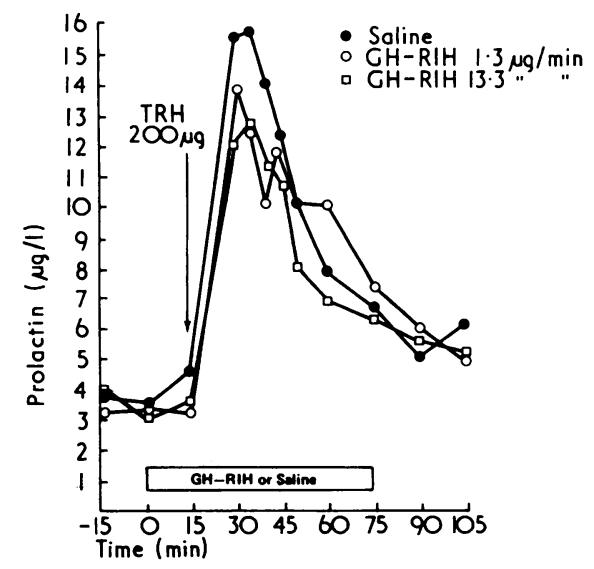

FIG. 2-Effects of GH-RIH and saline on TRH-mediated prolactin release. Results are mean data from six normal men.

\section{HYPOTHYROID PATIENTS}

The thyrotrophin response to an injection of $200 \mu \mathrm{g}$ of TRH was impaired, though not completely abolished, by GH-RIH $1000 \mu \mathrm{g}$ over 75 minutes in all three patients with raised basal thyrotrophin levels (fig. 3).

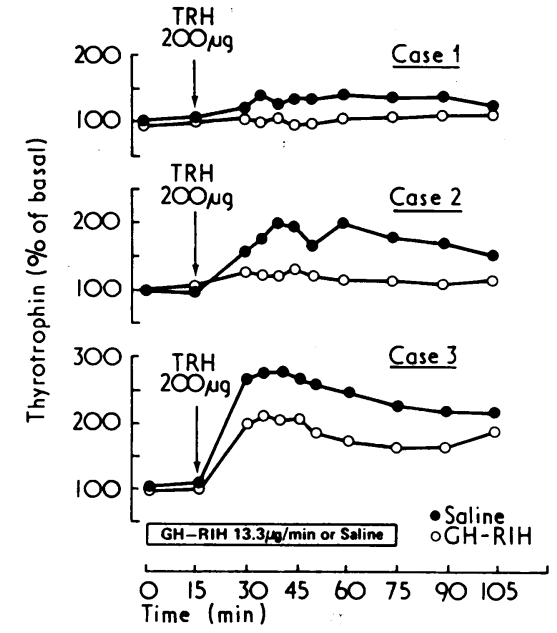

FIG. 3-Effects of GH-RIH and saline on TRH-mediated thyrotrophin release in three patients with primary hypothyroidism.

\section{Discussion}

These results confirm our preliminary observation that the thyrotrophin response to TRH is inhibited by GH-RIH ${ }^{1}$ and show that a similar inhibition occurs in patients with primary hypothyroidism. They also support observations on human subjects in other studies where different doses of the hormones were used. ${ }^{8}$ The degree of inhibition of the thyrotrophin response to TRH depends on the dose of GH-RIH used, being much greater at an infusion rate of $13.3 \mu \mathrm{g} / \mathrm{min}$ than at a rate of $1.3 \mu \mathrm{g} / \mathrm{min}$. This contrasts with the response of growth hormone $(\mathrm{GH})$ in acromegaly, where infusions of GH-RIH at these doses are equally effective. ${ }^{15}$ That a higher dose of GH-RIH is necessary to inhibit the thyrotrophin response to TRH than to lower $\mathrm{GH}$ perhaps indicates that the interaction with TRH is pharmacological and has no physiological significance. A similar conclusion was reached from an in-vivo study in mice, in which larger amounts of GH-RIH, compared with T-3 on a molar basis, were needed to block the thyrotrophin response to TRH. ${ }^{16}$

The use of a higher dose of TRH $(800 \mu \mathrm{g})$ did not overcome the inhibitory action of GH-RIH on thyrotrophin release, which counters a suggestion that there is competitive inhibition between GH-RIH and TRH for the same receptor sites on the membrane of the thyrotroph. ${ }^{1}$ Similarly, competitive inhibition would not be expected from the results of in-vitro work, which suggests that GH-RIH acts distally to the site of action of cyclic adenosine monophosphate, ${ }^{1718}$ perhaps inhibiting exocytosis, ${ }^{19}$ whereas TRH acts on the membrane adenyl cyclase system to promote cyclic adenosine monophosphate formation, ${ }^{20}$ though further studies are required to define the precise -site of action of GH-RIH. Recent studies by Vale et al. ${ }^{9}$ also support the non-competitive nature of the inhibition of TRH by GH-RIH.

Basal thyrotrophin levels in animals ${ }^{9}$ and normal people are not obviously affected by short-term infusions of GH-RIH. Though this might suggest that basal thyrotrophin secretion does not directly depend on TRH drive longer infusions of GH-RIH are required to investigate this matter further.

Though GH-RIH blocks the thyrotrophin response to TRH it has no effect on the prolactin response to TRH. This dissociation of the thyrotrophin and prolactin responses to TRH by GH-RIH suggests different mechanisms for release of thyrotrophin and prolactin of which only the former is affected by GH-RIH. These responses to TRH may also be dissociated in hyperthyroidism, where the thyrotrophin response is completely abolished but the prolactin response merely blunted. ${ }^{21}$ Again, in isolated thyrotrophin deficiency the prolactin response to TRH was normal when the thyrotrophin response was absent. ${ }^{22}$

It may be of interest to use GH-RIH as a pharmacological tool in further studies of TRH action and thyrotrophin secretion, 
but it seems unlikely that the effects that we have described here will be important when GH-RIH is considered as treatment in cases of $\mathrm{GH}$ excess, though long-term studies are needed in normal people and in those with pituitary disease.

We thank Dr. D. C. Evered for his courtesy in estimating T-3 and T-4 and Dr. H. Friesen for providing the purified human pituitary prolactin. We also acknowledge the financial support of the Scientific and Research Committee of the Newcastle Area Health Authority (Teaching), the Veterans Administration, and Tulane University and the excellent secretarial help of Mrs. M. E. Shepherd.

Requests for reprints should be addressed to Professor R. Hall, Endocrine Unit, Department of Medicine, Royal Victoria Infirmary, Newcastle upon Tyne.

\section{References}

${ }^{1}$ Hall, R., et al., Lancet, 1973, 2, 581.

${ }^{2}$ Hansen, A. P., et al., British Medical fournal, 1973, 3, 523.

${ }^{3}$ Siler, T. M., et al., fournal of Clinical Endocrinology and Metabolism, $1973,37,632$

${ }^{4}$ Alberti, K. G. M. M., et al., Lancet, 1973, 2, 1299.
5 Mortimer, C. H., et al., Lancet, 1974, 1, 697

${ }^{6}$ Bloom, S. R., et al., Lancet, 1974, 2, 1106.

7 Siler, T. M., et al., Fournal of Clinical Endocrinology and Metabolism, 1974, 38, 742 .

${ }^{8}$ Weeke, J., Hansen, A. P., and Lundbaek, K., Scandinavian fournal of Clinical and Laboratory Investigation, 1974, 33, 101.

${ }^{9}$ Vale, W., et al., Endocrinology, 1974, 95, 968.

10 Evered, D. C., et al., British Medical fournal, 1973, 1, 657.

11 Coy, D. H., et al., Biochemical and Biophysical Research Communications, 1973, 54, 1267.

12 Hall, R., Amos, J., and Ormston, B. J., British Medical fournal, 1971, 1, 582 .

${ }_{13}$ McNeilly, A. S., and Hagen, C., Clinical Endocrinology, 1974, 3, 427.

14 Hesch, R. D., and Evered, D. C., British Medical fournal, 1973, 1, 645.

15 Besser, G. M., et al., British Medical fournal, 1974, 1, 352.

16 Bowers, C. Y., et al., Federation Proceedings, 1974, 33, 263.

17 Borgeat, P., Biochemical and Biophysical Research Communications, 1974, 56, 1052.

${ }^{18}$ Labrie, F., et al., Proceedings of the National Academy of Sciences of The United States of America, in press.

19 Schofield, J. G., Mira, F., and Orci, L., Diabetologia, 1974, 10, 357.

${ }^{20}$ Labrie, F., et al., Proceedings of the National Academy of Sciences of The United States of America, 1972, 69, 283.

${ }^{21}$ Bowers, C. Y., Friesen, H. G., and Hwang, P., Biochemical and Biophysical Research Communications, 1971, 45, 1033.

22 Sachson, R., et al., New England fournal of Medicine, 1972, 287, 972.

\title{
Indomethacin-Aspirin Interaction: A Clinical Appraisal
}

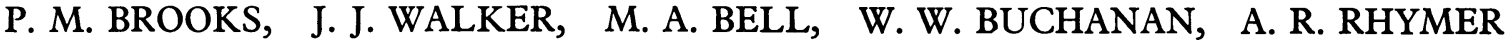

British Medical fournal, 1975, 3, 69-71

\section{Summary}

Plasma profiles of indomethacin after a 50-mg oral dose were constructed in six healthy volunteers before and after a week of aspirin treatment. Aspirin did not interfere with indomethacin plasma levels.

To examine the clinical effect of concurrent indomethacin and aspirin treatment 20 patients with seropositive rheumatoid arthritis were given indomethacin $100 \mathrm{mg}$ / day, aspirin soluble $4 \mathrm{~g} / \mathrm{day}$, and the two drugs taken together in random order. Analysis of the clinical indices of inflammation-articular index and mean pain scoreand of the efficacy of each treatment showed no significant differences between the three treatment groups.

With the proliferation in the number of anti-rheumatic drugs available, the case for giving two or more nonsteroidal anti-inflammatory drugs concurrently remains unproved.

\section{Introduction}

There is still controversy about the effect of concurrent aspirin treatment on plasma indomethacin levels, and as aspirin and indomethacin are commonly used together ${ }^{1}$ it is important to establish the clinical significance of any interaction. We assessed the effect of aspirin administration on plasma indomethacin

\footnotetext{
Centre for Rheumatic Diseases and University Department of Medicine, Royal Infirmary, Glasgow

P. M. BROOKS, F.R.A.C.P., Robins Research Fellow

J. J. WALKER, Medical Student

M. A. BELL, .A.I.M.L.T, Senior Technician

W. W. BUCHANAN, F.R.C.P., Professor of Medicine

Merck, Sharp And Dohme Ltd., Hoddesdon, Herts

A. R. RHYMER, M.R.C.P., Clinical Research Physician
}

profiles in normal people and also investigated the clinical effect of each drug alone and in combination by a double-blind crossover assessment in 20 patients with rheumatoid arthritis.

\section{Patients and Methods}

Profile Study.-After a light breakfast indomethacin $50 \mathrm{mg}$ was given by mouth to six normal people and blood was collected then and at $30,60,90,120,180$, and 240 minutes after ingestion. Soluble aspirin $4 \mathrm{~g} /$ day was then given for one week using soluble aspirin $500-\mathrm{mg}$ tablets in four equal doses and the indomethacin $50-\mathrm{mg}$ profile was repeated.

Double-blind Crossover Study.-Twenty patients with seropositive rheumatoid arthritis according to the American Rheumatism Association criteria were also studied. The mean age of the patients was 56.2 years and the mean duration of disease was 8.2 years. The patients were given in random order two-week treatment periods of aspirin and placebo, placebo and indomethacin, and aspirin and indomethacin. The treatments were randomized using a Latin square matrix. The patients were assessed by a single observer at the same time of day on day 14 of each treatment period. Standard methodology was used for measuring an articular index of joint tenderness, ${ }^{2}$ grip strength in the right and left hand, ${ }^{3}$ and pain score. ${ }^{22}$ The patients were given a chart on which they recorded the degree of joint pain each night before they retired to bed. ${ }^{22}$ At the end of the trial patients were asked to compare the three treatment regimens. For statistical purposes the efficacy ratings were given a total score of $9: 5$ for the most preferable, 3 for the next most preferable, and 1 for the least preferable treatment. If two treatments were equal the points available after consideration of the other treatment were divided equally.

Plasma indomethacin levels were measured using the spectrofluorimetric method ${ }^{4}$ of Hucker with the modification described by Emori. ${ }^{5}$ There was no interference with the indomethacin assay when aspirin $10 \mathrm{mg} / 100 \mathrm{ml}$ or $20 \mathrm{mg} / 100 \mathrm{ml}$ was added to plasma standards containing $2 \mu \mathrm{g} / \mathrm{ml}$ or $5 \mu \mathrm{g} / \mathrm{ml}$ of indomethacin. The results were analysed statistically using Student's $t$ test for paired values.

\section{Results}

Profile Study.-The results of the plasma profiles of a $50-\mathrm{mg}$ oral indomethacin dose before and after a seven-day course of aspirin 